\title{
Realizando grupos focais como estratégia de reflexão no desenvolvimento profissional de professores de Matemática na EJA
}

\author{
Marcelo Almeida Bairral \\ Universidade Federal Rural do Rio de Janeiro \\ mbairral@ufrrj.br
}

Agnaldo da Conceição Esquincalha

Universidade do Estado do Rio de Janeiro

agnaldo.esquincalha@uerj.br

Gisela Maria da Fonseca Pinto

Universidade Federal Rural do Rio de Janeiro

giselapinto@ufrrj.br

Gisele Pereira de Oliveira Xavier

Prefeitura Municipal de Japeri

gisele_po@msn.com

\begin{abstract}
Resumo
Políticas Públicas (PP) voltadas para o desenvolvimento profissional de docentes da Educação Básica têm sido frequentes no contexto brasileiro. Todavia, a avaliação dessas PP, principalmente, das que envolvem temáticas emergentes ainda é incipiente. Neste artigo, o foco é elucidar reflexões docentes sobre a formação continuada em serviço para a Educação de Jovens e Adultos na rede estadual fluminense, a Nova EJA. A principal fonte de coleta e análise de dados constitui-se de grupos focais videogravados e, mediante análise descritiva, elucidamos categorias que podem ser úteis na constituição e avaliação de PP de desenvolvimento profissional em matemática para EJA. $\mathrm{O}$ estudo ressalta que uma PP de formação em serviço considere, no mínimo, três âmbitos no desenvolvimento profissional dos educadores: suas concepções sobre a especificidade da EJA, atenção para a elaboração de um material didático articulado aos propósitos dessa modalidade e que seja efetivada em uma dinâmica formativa que propicie reflexões presenciais e compartilhamentos online constantes.
\end{abstract}

Palavras-chave: Formação continuada de professores. EJA. Reflexão docente. Âmbitos formativos. Grupo focal. 


\title{
Promoting focal groups as strategies of reflection on mathematics teachers professional development for Youth and Adult Education
}

\begin{abstract}
Public policies (PP) focused on the professional development of teachers for Basic Education has been occurring frequently in Brazilian context. However, the evaluation of PP, especially those involving emerging themes is still scarce. In this article we focus on New EJA, a state policy of Rio de Janeiro focused on in service teacher program for Youth and Adults Education (YAE). Our main source of data collection and data analysis consists of video-recorded focus groups and through descriptive analysis elucidated categories that may be useful in the formation of PP professional development in mathematics for EJA. The study highlights that a PP in-service training consider at least three realms in the professional development of educators: his conceptions regarding the specificity of YAE, the attention for the elaboration of didactic materials articulated with the purposes of the YAE, and a formative program that provides face to face and online continuously reflections.
\end{abstract}

Keywords: In-service teacher education. EYA. Formative realms. Focal group.

\section{Introdução}

“Eu trabalho com resolução de problemas matemáticos, $e$ muitas questões eu pego desse material para trabalhar no regular."

Professora de Itaperuna $(R J)$

A Educação de Jovens e Adultos (EJA) é uma modalidade de ensino que tradicionalmente apresenta uma série de dificuldades (evasão, desmotivação para o retorno ao estudo, dissociação entre experiências cotidianas e conteúdos escolares, falta de material didático apropriado, dentre outras) com as quais o aprendiz tem que lidar para retornar à escola. Essas limitações podem se agravar quando os professores não possuem formação para lidar com as mesmas.

A Nova EJA ${ }^{2}$ (NEJA) é uma política de Educação de Jovens e Adultos implementada em 2013 com alunos em todas as escolas estaduais que ofertam Ensino Médio nesta modalidade. Segundo o Manual de Orientações (RIO DE JANEIRO, 2015), a NEJA utiliza metodologia e

\footnotetext{
${ }^{1}$ Leia Paiva e Sales (2013) para conhecer uma importante reflexão sobre quem são atualmente os alunos da EJA. Esse coletivo é composto de "um conjunto amplo e heterogêneo de jovens e adultos" (p. 6). Nessa diversidade de alunos, excluídos, não crianças, alguns têm tido visibilidade em pesquisas ou em políticas públicas e assumido identidades sociais singulares, por exemplo, os sujeitos do campo, os internos penitenciários, os quilombolas e os surdos (p. 6).

${ }^{2}$ A partir de 2015 o Programa Nova EJA passou a ser chamado apenas de EJA, pois os quatro módulos já haviam sido implementados, descaracterizando o Programa como novo. No entanto, a fim de não confundir a modalidade com o Programa, usaremos Nova EJA ao longo deste texto.
} 
currículos específicos para jovens e adultos, material didático e do professor próprios e recursos multimídia. Os professores da NEJA ainda participam de um curso de formação continuada específico. Estruturalmente, o ciclo completo da NEJA dura dois anos divididos em quatro módulos, um a cada semestre, que alternam a ênfase em disciplinas da área das Ciências da Natureza com disciplinas da área das Ciências Humanas. Por outro lado, Língua Portuguesa e Matemática estão presentes em todos os quatro módulos.

Neste artigo, analisamos a formação continuada na NEJA e, particularmente, identificamos contribuições de sua dinâmica de trabalho no desenvolvimento profissional dos professores de matemática $^{3}$, levando em consideração o próprio posicionamento dos educadores. Mediante implementação e análise de grupos focais (GF) em três polos (Região Serrana, Metropolitana e Noroeste Fluminense) de formação, o presente estudo valoriza a reflexão com os próprios educadores (FREITAS e RIBEIRO, 2014) sobre a sua prática e sobre a contribuição do Programa NEJA para seu aprendizado.

\section{Material didático e formação docente no Programa NEJA}

Segundo Esquincalha et al. (2014), a organização do material didático, que é usado pelo discente em aula, foi feita por uma equipe de professores com experiência em EJA, mas com desenho instrucional apropriado à modalidade Educação a Distância $(\mathrm{EaD})$. Portanto, esse material tem características de interação com o aluno, o que permite que ele estude sozinho, de maneira autônoma. As unidades do material didático procuram se relacionar com aspectos da vida cotidiana, adulta e profissional, enfocando situações que motivem o estudo de matemática e que justifiquem o seu aprendizado. Apesar de usar o material elaborado para EaD, o estudante da NEJA estuda presencialmente, frequentando a escola de segunda à sexta durante três horas e vinte minutos por dia.

Paralelamente ao material do aluno, o professor tem também um outro elaborado por outra equipe, com experiência em formação de professores, que organiza e propõe atividades que possam ser aplicadas em sala de aula. O material do professor sempre oferece recursos digitais que ele pode usar com seus alunos. Os contextos desses recursos se propõem a motivar o desenvolvimento de conceitos matemáticos e a sua exploração a partir de vídeos, jogos, músicas ou animações. Analisando o material didático, Esquincalha e Pinto (2015) apontam que há uma preocupação em que a metodologia de abordagem usada pelo professor seja a da resolução de problemas, na qual o

\footnotetext{
${ }^{3}$ Pesquisa financiada pela Fundação CECIERJ.
} 
educador possa inicialmente avaliar as habilidades dos estudantes e propor atividades que estimulem o desenvolvimento do seu raciocínio.

Além da atuação em sala de aula, os professores da NEJA encontram-se também em processo de formação continuada semipresencial, com encontros presenciais mensais com oito horas de duração e com formação online contínua no Ambiente Virtual de Aprendizagem. Neste artigo, analisaremos apenas uma das dinâmicas avaliativas presenciais: os grupos focais em polos de formação presencial. Partimos do princípio que políticas públicas de desenvolvimento profissional docente, além de serem balizadas pela reflexão e aprendizagem e oportunizadas pela avaliação (SILVA et al., 2013; TASCA et al., 2013), devem buscar formas diferenciadas de acompanhamento da prática e da motivação do educador para continuar aprendendo, inovando e aprimorando sua docência.

\section{Procedimentos metodológicos do estudo}

Como estratégia de formação e pesquisa os grupos focais são importantes porque permitem evidenciar opiniões, relevâncias, valores, crenças e percepções dos sujeitos; possibilitam focalizar a investigação em questões mais precisas; e enriquecem a coleta de dados (BERG, 2006; MINAYO, 1996).

Os grupos focais (GF) versaram sobre: (a) o ensino de matemática de maneira contextualizada ao cotidiano, (b) atividades específicas para o público da EJA e (c) a importância das experiências compartilhadas que podem ocorrer por meio dos fóruns de discussão. Os GF foram planejados e realizados - no segundo semestre de 2013 - em três polos distintos. Aproveitamos os encontros para formação presencial dos professores de Matemática do Programa NEJA, nos polos São João de Meriti (Baixada Fluminense - cerca de 35 participantes), Itaperuna (Noroeste Fluminense - cerca de 30 participantes) e Nova Friburgo (Região Serrana - cerca de 20 participantes). Esses três polos foram selecionados a partir da análise quantitativa de postagem nos fóruns $^{4}$ e pela sua localização geográfica no estado do Rio de Janeiro.

Foram elaboradas três atividades focais a partir de situações reais da Formação Continuada para NEJA. Consideramos planos de ação propostos pelos cursistas e sequências de comentários em fóruns de discussão. Os grupos focais foram filmados ${ }^{5}$, com a concordância prévia dos professores, após o esclarecimento do propósito dos GF. A duração média dos GF foi de uma hora e trinta minutos.

\footnotetext{
${ }^{4}$ Foi realizada uma tabulação voltada para o número de postagens. Essas três regiões tiveram um grande número postagens na maioria das unidades temáticas.

${ }^{5}$ Agradecemos ao tutor Rodrigo Ramos de Souza pela colaboração na filmagem em Itaperuna.
} 
Os vídeos foram assistidos recorrentemente pelos pesquisadores, que transcreveram algumas falas dos cursistas e as organizaram em quatro blocos, a saber: (1) Educação de Jovens e Adultos, (2) indícios de aprendizado do professor, (3) material didático e (4) sugestões. Em cada bloco, elencamos subcategorias e a análise assumiu um cunho descritivo, pois consideramos que esse tipo de interpretação é pertinente em ações formativas nas quais os sujeitos da investigação possuem pouca vivência ou familiaridade com o objeto de análise (BERG, 2006).

\section{Análises das transcrições dos grupos focais}

Após a visita recorrente aos vídeos e conversas entre a equipe de pesquisa, organizamos e preenchemos uma grande tabela com trechos das falas dos professores em formação, dispostas em subcategorias dos quatro blocos anteriormente citados. Em seguida, selecionamos as transcrições que serão objeto de reflexão neste artigo. Indicamos em sombreado e itálico as "falas" para análise.

Embora os blocos temáticos não sejam excludentes, o que fizemos foi exemplificar algo na reflexão do docente que pode ter uma relação direta com o bloco. Observamos que a maioria deles poderia ser ilustrada com falas de um único professor, mas optamos por ilustrar reflexões de docentes diversos.

A seguir, ilustramos e analisamos algumas das transcrições feitas. Nelas, observamos o posicionamento dos cursistas em relação às diferentes frentes do Programa NEJA e como essas têm contribuído com as suas atividades profissionais.

\section{Sobre o bloco temático Educação de Jovens e Adultos}

Nesse bloco, emergiram cinco âmbitos de reflexões dos docentes: 1) a percepção deles sobre a necessidade de uma formação específica para a EJA, 2) suas concepções e aparente clareza sobre o propósito da EJA, 3) a NEJA como uma política pública, e 4) atenção dos educadores para a avaliação do aprendizado na EJA, e 5) a importância de dar voz ao conhecimento do aluno. Vejamos.

Subcategoria 1: Percepção da formação específica para EJA

Professora com blusa de listras preta e branca $\left(\mathrm{PBLPB}^{6}\right)$ : "E eu tive uma aluna que falou para mim assim: - eu acho que estou aprendendo mais do que meus quatro meninos do ensino regular. Porque a abordagem é muito contextualizada ${ }^{7}$, né? Por causa da maturidade da clientela da NEJA, a gente pode entrar. Como por exemplo, esta unidade de conjuntos aqui. Gente! Como eu adorei trabalhar com

\footnotetext{
${ }^{6}$ Códigos criados para manter o anonimato dos participantes.

${ }^{7}$ Negritos nossos.
} 
esta unidade. A abordagem foi feita, como foi conduzida, o desenvolvimento da teoria de conjuntos, como se organizam conjuntos. A preciosidade da organização do tempo, eu fiquei apaixonada. Como no ensino regular, a gente não tem isso daqui. De repente, a gente não tinha nem ideia de como fazer dessa forma. Eu achei o material da formação riquíssimo. E a fala dessa aluna, eu achei bastante interessante".

Professora de blusa estampada (PBE): "Eu trabalho com resolução de problemas matemáticos e muitas questões eu pego desse material para trabalhar no regular. Entendeu?! E você vê que os alunos do regular, eles viajam um pouquinho, mas, acabam sendo motivados pela contextualização. Então, aí, você consegue comparar os alunos da NEJA com eles, entendeu?! E o resultado da NEJA é bem significativo. Entendeu?! Dá.. dá... o diferencial está na maturidade deles. Mas, é um material que está riquíssimo até para o regular".

De um modo geral, os professores aparentam valorizar a abordagem da formação e de seus materiais. Destacam a potencialidade de envolver conhecimentos que são abordados no Ensino Médio. Apreciam o material focar na contextualização dos assuntos. As professoras PBLPB e PBE destacam a motivação demonstrada pelos alunos ao trabalharem com atividades mais "maduras", isto é, com a linguagem e contextos inerentes a prática diária dos jovens e adultos.

A professora PBLPB demonstrou aprendizado ao conhecer novas formas de abordar determinados conteúdos, o que tem trazido grande satisfação tanto pelo conhecimento de novas metodologias como pela motivação demonstrada pelos alunos dos professores em formação. A docente PBE comentou a reutilização do material em outras turmas como o ensino regular.

Comparam o comportamento dos alunos no ensino regular e na NEJA frente às atividades, percebendo que ambos são motivados pela contextualização. No entanto, destacam (PBLPB e PBE) que a maturidade dos alunos da NEJA as deixa mais à vontade e motivadas ao experimentarem as atividades propostas no material.

Subcategoria 2: Concepções dos professores e clareza quanto às especificidades da EJA

Professor de blusa verde (PBV): "porque falar a linguagem dessas pessoas, além de passar a linguagem do conteúdo, nos obriga muito a ter outros aspectos em sala de aula".

Professor de rosa (PR): "se você puder usar a realidade dele, para facilitar... é... a sua introdução com a linguagem matemática... é ótimo, isso é ótimo... (reforçando com a cabeça) porque ele já tem uma vivência, porque ele já tem uma visão, já entende o que é aquilo, só que cabe a você (trazendo as mãos para si, atribuindo-se a responsabilidade) organizar igual ele está falando (referindo-se a uma fala anterior do moderador), facilitar, né? Se você puder trazer a realidade dele, vai ficar muito mais fácil para ele aprender com certeza".

Professora de casaco preto e blusa rosa (PCPBR): “...uma coisa que o colega falou, para o aluno da EJA, se você não dá uma aplicação imediata para ele, se você nãa dá um motivo para ele aprender aquilo, ele abstrai, ele passa à porta... e acabou". 
Os trechos destacados indicam algumas concepções dos cursistas a respeito das especificidades da EJA. Os cursistas refletem sobre a necessidade de uma linguagem adaptada para o público da EJA, que vai além de adequação de conteúdos, ressaltando que estes precisam ser explorados de maneira contextualizada, a partir da realidade dos alunos. Na EJA, o aluno precisa saber a utilidade do que está sendo estudado, ainda que seja apenas para a própria Matemática. Utilizando os conhecimentos que os alunos trazem, o professor pode construir a linguagem e o ferramental matemático necessário para a abstração, por exemplo.

Subcategoria 3: NEJA como política pública: uma preocupação com avaliações externas

Professor de camisa polo listrada (PCPL): “(...) vai vir uma prova externa, $\boldsymbol{e}$ o que será que vai cobrar nessa prova? (...) No currículo mínimo da EJA, da NEJA, mas o currículo mínimo está paralelo (...)".

Professor de camisa azul-claro (PCAC): “(...) o currículo mínimo está paralelo, mas num nível de cobrança bem abaixo na EJA.".

A preocupação com os exames sistêmicos tem permeado as ações pedagógicas públicas de maneira geral - e, como não podia ser diferente, também na EJA. A influência dessas provas acaba por se refletir na sala de aula delimitando novas ações docentes: a preocupação em preparar para fazer a prova acaba sendo maior que aquela que procurava dar conta do currículo e promover o alcance dos objetivos presentes no plano do curso. A fala do professor mostra a angústia com a EJA em particular, notando ser esta uma modalidade que normalmente trabalha com recortes nos conteúdos - será que esses recortes, o que foi deixado de lado, não irá acarretar prejuízo de resultado de avaliação para aquele aluno, consequentemente, para a turma, para o professor e para a escola? Quando consideramos a política de gratificações resultante de um conjunto de itens avaliados dentre os quais o resultado de tais provas destaca-se, tal preocupação é pertinente.

\section{Subcategoria 4: Atenção para a avaliação do aprendizado na EJA}

Professor com a camisa do Fluminense comentando sobre contextualizar as atividades (PCF): “(...) mas no bate-papo dele, você levando aquela situação para sala de aula, ele vai levantar a mão e te dar a resposta na lata, agora botou no papel..." (sinaliza indicando que o aluno não consegue responder).

Nesse intervalo, o cursista pontua a importância da valorização do conhecimento não formal dos alunos da EJA, ressaltando que muitas vezes eles são capazes de resolver um problema, mas lhes falta ferramental matemático para formalizar a solução. Mais uma vez fica sinalizada a necessidade de utilizar os conhecimentos prévios dos alunos e utilizá-los como ponto de partida para a construção do conhecimento matemático formal. 
Professora de blusa branca (PBB): "Na EJA, o interessante é isso, porque ali, todos, na maioria, trabalham. Às vezes tem um jovem, dois, três que estão ali por falta de disciplina, ou porque não conseguiram acompanhar de manhã e foram para a noite. Mas, a maioria no curso é essa, porque eles trabalham, nunca para uma profissão. Então, dependendo do assunto que se esteja trabalhando em sala, cada um traz para sua realidade. Por exemplo, eu dei... É, eu tenho um aluno que vende material de construção, trabalha no comércio vende material de construção e também trabalha com isso. Quantidade de tintas a gente trabalhou para a área. Então, se gasta tanto de tinta, que quantidade vai gastar para essa área? Aí, ele trouxe isso para a gente trabalhar essa realidade também. E em outros assuntos também, como equação do primeiro grau, quem tem a incógnita, que tem a parte fixa... função do primeiro grau, que tem a parte fixa e tem a parte que varia: a variável. E, no comércio, de certa forma eles usam. Então, sempre trazem essa realidade. Então a gente pode fazer dialogando, né? Muito bom".

A professora-cursista PBB comenta que, por grande parte dos alunos da NEJA trabalharem, é mais fácil relacionar o conhecimento matemático à prática. $\mathrm{O}$ que facilita na construção e estruturação do raciocínio e consequentemente na assimilação e acomodação do aprendizado matemático. Menciona o fato de que os alunos relacionam as experiências de sala aula com suas atividades no trabalho, o que enriquece o aprendizado, visto que grande parte compartilha suas experiências e dúvidas com a turma e com o professor, que por sua vez aproveita o conhecimento e a voz que é levada por esses alunos.

\section{Sobre o bloco temático Indícios de aprendizado do professor}

Nesse bloco, emergiram quatro subcategorias que remetem à reflexão dos docentes: 1) exemplos de falas, olhares, sinais de concordância, 2) medos, inseguranças e dúvidas, 3) aprendizado de ordem tecnológica (informática), e 4) desenvolvimento da autonomia mediante estratégias didáticas criadas, inspiradas etc. Vejamos.

Subcategoria 1: Exemplos de falas, olhares e sinais de concordância sobre o aprendizado discente

Professor de blusa cinza (PBC): "Minha escola não atingiu a meta do ano passado, de aprovação-reprovação, sendo que a média estadual externa está com as melhores notas da região. Assim, sempre tendo hum... com as primeiras notas da região. Aí, vira a coordenação para mim: porque vocês têm uma nota tão boa externamente e internamente vocês têm..., ops, desculpe, internamente vocês estão com esses problemas de média. Ué, nós como professores respondemos: ué, porque nosso nível de ensino é muito, muito mais avançado do que o que vocês cobram aí fora. A gente está num...".

Professora de blusa branca (PBB): "É porque saem e conseguem atingir lá fora, né??"' (concordando com a fala do professor de cinza).

Professor de blusa cinza (PBC): "Exatamente!” 
Professora de blusa rosa (PBR): "Porque um aluno do noturno faltou, aí, precisava daquela pontuação para atingir. Então, eles não aceitaram nem os nossos argumentos. Então, a gente que já tinha uma nota alta, a gente ia mais alto do que a gente já tinha. Aí, como esse aluno não compareceu, a nota não foi. Aí, há um desânimo na escola muito grande, né?! Não, no trabalho que a gente vai continuar fazendo. Mas a gente pensa assim: a gente não tem que nem pensar em vocês lá, né? neles. Porque na verdade não olham por nós. A gente tem que aprovar um aluno. A gente tem aprovar praticamente um aluno, que não faz nada, porque tem presença. Vamos colocar assim. Mas, na hora em que a escola não atinge porque um aluno faltou, eles não olham isso lá".

Professor de blusa cinza (PBC): “... Tem um trabalho sendo omisso, ponto. Eu não estou questionando a visão dele não. Esse é número, você atingiu aquele número, está bom. Não atingiu, tem nem como...".

Professora de blusa rosa (PBR): "Hum, pode ser assim: tem que ver o que aconteceu do lado de fora; o aluno que foi embora; o que ele atingiu, o que ele conseguiu, aquele que saiu. O SAERJ são os últimos anos, né?! O que ele atingiu, se ele conseguiu alcançar alguma escola pública, federal, você está me entendendo? No caso, federal, né? Então, acho que eles tinham que avaliar em cima disso também, em cima de porcentagem, né? Dos alunos que vão embora. Alguma coisa boa".

No discurso dos professores nota-se que, apesar da dedicação e do foco que a escola tem dado e da prática pedagógica estar preocupada com o desenvolvimento e aprendizagem dos alunos, não há acompanhamento dessas práticas através da avaliação interna (índices de aprovaçãoreprovação). Discordam da pressão que essa meta representa, sendo induzidos muitas vezes a ter que aprovar um aluno que não faz nada, porque tem presença. Sentem-se desestimulados por essa situação e pelo fato da omissão das avaliações externas. Pois não é feito nenhum trabalho de averiguação das circunstâncias e do acompanhamento até mesmo dos alunos. O que acaba prejudicando o trabalho que eles desenvolvem.

Subcategoria 2: Medos, inseguranças e dúvidas explicitadas

Professora de camiseta vermelha (PBVm): “(...) então eu acho que a maior dificuldade, assim, no meu ver, eu vejo muito, por essa fala do meu pai, entendeu, é... "eu não vou estudar por causa da sua matemática", porque a minha matemática é diferente da matemática dele. A matemática dele é... é... é outra, parece que a minha é de outro mundo, entendeu? E não é! Só que colocar em outra linguagem para ele, no caso da EJA, ele já é uma pessoa com 60 anos, 65, que é o que nós temos, eu tinha uma aluna com 60 anos, então a linguagem dele é totalmente diferente da minha, da que eu quero passar para ele, a gente até tenta, mas é muito difícil."

Cursista comenta sobre a dificuldade de encontrar uma linguagem adequada para o público da EJA, em particular, para alunos mais idosos que comumente desistem de estudar por não compreenderem a linguagem utilizada pelos professores de Matemática. 
Subcategoria 3: Aprendizado de ordem tecnológica (informática)

Nesta subcategoria as reflexões dos docentes estiveram circunscritas à dinâmica de formação semipresencial e ao uso do GeoGebra, um software preconizado em algumas atividades formativas.

Professora de blusa estampada (PBE): "O que eu gostei na realidade; porque eu fiz o outro também da Formação Continuada do Regular. O que eu achei diferencial na NEJA é justamente esse contato nosso. Parece que se completam, né? Então, às vezes, muita vontade dos colegas, atividades que eles mostram, a gente aproveita, usa na sala. Depois, a gente dá retorno como foi, entendeu, né? Eu acho muito válido! No nosso grupo em si, né?".

Professora de blusa salmão (PBS): “O que é mais próximo, do que a rigor a gente fica muito longe dos problemas".

Professora de blusa estampada (PBE): "Na realidade, as pessoas colocavam coisas que a gente, assim, acha, poxa! Meu colega tem uma turma diferente da minha, porque se ele consegue falar dessa maneira e colocar dessa maneira. Meu Deus, eu estou perdida! Porque na minha eu não consigo! Aqui não! A gente troca figurinha entendeu, a gente tem contato. Eu sei que a minha dificuldade, é a dificuldade do colega, do outro colega. Então, ela fez uma coisa lá... olha gente, isso aqui, esse problema assim, assim e tal. Aí, eu vi aquilo, corri, imprimi, e coloquei na sala. E dou retorno a ela. Olha! Eu fiz assim... entendeu. Então, eu acho muito válido, muito rico, essa troca nossa. Além das questões propostas, que às vezes estão fazendo a gente olhar o material, né? Porque as abordagens têm que ser de maneira que você é obrigado a olhar tudo, né. Ele está conduzindo para esse lado. E fora essa troca nossa, que eu acho que é muito rica. Eu meço no nosso grupo, né?".

A professora-cursista PBE destaca e valoriza a proposta do curso em propiciar os encontros presenciais, que oportunizam não só a reunião e o contato com os demais professores cursistas, mas também é mais um ambiente que amplia as discussões e questionamentos, além de poderem trocar experiências e conhecimentos. Comenta que se sente à vontade, pois percebe que muitas vezes a realidade do colega também é a sua realidade e que juntos podem buscar soluções e melhorias. Considera essa oportunidade muito rica, pois fornece outro olhar para a prática pedagógica e a forma de abordar os conhecimentos.

Subcategoria 4: Desenvolvimento da autonomia mediante estratégias didáticas criadas, inspiradas etc.

Professora de blusa cinza e rabo de cavalo (PBCRC), respondendo sobre métodos diferentes para trabalhar área: "Eu trabalhei com pintura na sala de aula no ano passado, porque quando eu comecei a dar área, eu vi que eles tinham muita dificuldade, entender, assim, que quadrilátero não é só quadrado. Aí, eu montei uma malha com losango, retângulo e quadrados, e pedi que eles pintassem de cores diferentes né? Que escolhessem uma cor para os retângulos, uma cor para o losango e uma para o quadrado. Então, eles tinham que usar a mesma cor. Depois que eles coloriram - eles erraram muito (ênfase no muito) até conseguir fazer porque ai "Ah, professora, mas esse é igual àquele? Não, no meu está diferente!". 
E então cada um gastou uma média de três a quatro cópias para pintar certinho. "Mas a senhora vai dar pintura, a senhora não dá aula de artes, como assim?!" (entonação de espanto simulando a expressão do aluno). Assim, depois que todo mundo fez, eu expus na sala e eles ficaram todos orgulhosos porque tinha exposição deles. Depois desse processo... Mas isso eu demorei assim umas quatro aulas na semana, uns dois dias pra conseguir fazer a pintura com eles. Depois que eles fizeram isso que sentiram as diferenças. Aí, eu entrei com o cálculo de área de quadriláteros. Para eles poderem entender que a área do quadrado não é calculada da mesma forma da área do losango, verem a diferença de um para o outro. Eu fiz esse trabalho de pintura. Perguntada sobre a validade da ação, responde: não foram quatro aulas perdidas, e tinha que ver a participação deles, aquelas senhorinhas, com muita dificuldade, pintando, um ajudando o outro, aí o pessoal vai vendo quem tem mais facilidade "não, deixa que eu te ajudo, eu vou te ajudar a pintar".

Essa professora ama o que faz. Pelo menos é o que sua fala deixa antever. Ela menciona apaixonadamente o trabalho que realizou com os alunos, especialmente, por ter percebido o sucesso alcançado com a sua proposta, que foi auxiliar os alunos a perceber os diferentes tipos de quadriláteros em relação às suas propriedades. O trabalho colaborativo com alunos que poderiam ser potencialmente conflitantes (idades e perfis culturais muito distintos) foi outro fato que mereceu destaque na fala da professora, quando os mais velhos foram auxiliados pelos mais novos voluntariamente. A atenção dos professores do grupo, presentes na sala, foi algo notável, pois todos estiveram bastante atentos, mostrando-se motivados em promover algo semelhante em suas salas de aula.

\section{Sobre o bloco temático Material Didático - NEJA}

Nesse bloco emergiram quatro subcategorias na reflexão dos docentes inerentes ao material didático da formação continuada: 1) algo significativo/novo, algo que o professor tem vontade de aprimorar/estudar mais, 2) Inspiração em atividades dos módulos, 3) fator tempo como limitação para implementar tudo, e 4) conteúdos críticos. Vejamos.

Subcategoria 1: Algo significativo/novo que o professor tem vontade de aprimorar/estudar mais

Professor de blusa branca com listras verdes (PBBLV): “... quando eu fui dar essa questão de área, eu estava com problema de horário, de espaço para completar essa parte. Então, o que eu fiz? Eu peguei barbantes, com medidas grandes. Levei o pessoal para a quadra e aí eu comecei a pedir para que eles formassem quadrados. E, aí, eu comecei... a partir, da área de um quadrado. Aquela coisa, ah, quando você traça uma diagonal... aí, eles mesmo estavam visualizando que, ali, eles estavam formando dois triângulos. Um quadrado pode fazer metade... $e$ um triângulo é a metade de um quadrado, e coisa e tal. Então, eu peguei essa minha correria, com o tempo que eu precisava para fechar essa parte de figuras planas e apelei. Que eu nunca realmente tinha feito isso. De levarem eles para a quadra para fazer essa questão do barbante. E, assim, trabalhei algumas áreas: retângulo, quadrado e triângulos. Outras áreas, tipo circunferência, né? Não 
consegui. Mas todos eles com... sempre concluíam com a questão da construção civil. Porque lá no meu serviço (referindo-se às experiências da vivência que os alunos foram trazendo)... E, era assim mesmo, você dava a situação para ele, e ele fazia rápido, mas, aí, quando você dava no papel, quando era para escrever... aí, já ficava mais complicado".

Moderador: "Você falou que nunca tinha feito isso. Em que sentido?"

Professor de blusa branca com listras verdes (PBBLV): "É, nunca... o trabalho, de você, do manual, de levar a turma para uma quadra, espaço e tal".

Professora de blusa verde (PBV): "Ainda mais em sala de aula... porque, eu acho que a necessidade me levou a fazer isso. Porque eu tinha que fechar o troço e não tinha tempo. Não vou ficar no quadro, porque vou me enrolar todo aqui... e vai ser só figura, então melhor se eu tivesse numa folha e tivesse dado. Eu levei para o quadro... Lá para a quadra, e funcionou mais como... Para mim... eu, uma aula, para eles foi mais um lazer, um bate-papo, assim, do que eles já estavam fazendo de casa, jâ".

Esse discurso se mostra interessante, pois apesar de reconhecer as atividades, que constam no material, como interessantes, os professores, muitas vezes, têm um certo receio de implementálas por ainda não terem se submetidos a experiências diferentes em sala de aula. Esse professor em sua fala demonstra que, pelo pouco tempo de que dispunha e pela possibilidade de experimentação que a atividade apresenta, seria uma ótima alternativa para que pudesse dar conta do conteúdo e, ao mesmo tempo, se adequar à carga horária que ainda tinha. Ele expõe que a experiência foi enriquecedora tanto para ele, que estava experimentando algo diferente em sua prática pedagógica, quanto para os alunos, pelas possibilidades de aprendizagens que o trabalho prático da experimentação proporcionou. Comentou que, além de facilitar a visualização e o fazer matemático, ficou muito mais fácil na hora de transpor para os signos matemáticos e ainda sobrou tempo para explanar outras observações. O professor disse que foi um momento de aprendizagem prazeroso e dinâmico que favoreceu a interação professor-aluno-conhecimento. Embora tenha optado pela atividade, pela necessidade em que se encontrava, reconhece o valor da sugestão que o material fornece.

Subcategoria 2: Inspiração em atividades dos módulos

Professora de blusa listrada com a manga preta (PBLMP): "Se você reparar o livro, no material do aluno tem aquela atividade que mostra, é, a figura, né?... dependendo das medidas dos lados, a área pode ser a mesma, né? E os perímetros vão variando. Daquela... é, da função. Lá é função; o lado está em função do perímetro".

É possível perceber que o professor-cursista, além de aproveitar e muitas vezes perceber uma nova forma de abordagem, também se sente inspirado com algumas propostas contidas no material. 
Professor de azul (PBA): “(...) e quando você fala para o aluno que vai fazer uma revisão, parece que ele estava pesado" (professor se movimenta indicando que o aluno tira um peso dos ombros).

Professora de blusa branca (PBB): “isso! Ele fala: “o professor está do meu lado”, ele acha, a princípio, que a gente é do lado oposto, e, aí, quando você fala "não, nós vamos revisar, você pode tirar dúvida, perguntar", ai ele "ahhh"." (expressão de alívio).

Professor de óculos (PO): "automaticamente tem um fator com que a gente precisa se preocupar, principalmente, na NEJA, que é o tempo, né? (...) quando a gente para, para ajudar esse aluno, porque a gente tem que ajudar, né? E, aí, esbarra no tempo de dar o que tem que ser dado (...)".

Cursistas colocam sua angústia a respeito do tempo limitado para a realização de todas as atividades que julgam importantes para o aluno. De um lado, a necessidade de cumprir o cronograma, de outro, a necessidade de revisitar pré-requisitos necessários para a construção dos conceitos em voga, e que, normalmente, os alunos não lembram ou nunca estudaram.

Subcategoria 4: Conteúdos matemáticos críticos ${ }^{8}$

Professor de camisa listrada (PCL): "O que eu vejo com relação aos alunos, a essa dificuldade com eles, para mim é tudo uma base, e a base os alunos começam a aprender a partir dos números naturais, um, dois, três, faz uma sequência, você faz operações com esses números com eles, eles conseguem entender muito bem. Você sabe que os alunos têm a maior dificuldade com valor negativo, têm o problema com número negativo e com a divisão, eles ficam loucos com isso. Você fala assim com eles, quanto é três mais dois, eles sabem três mais dois na ponta da língua, mas fala quanto é dois menos três eles ficam doidos e falam que não dá. Mas por que não dá, dois menos três, não dá para fazer? Porque eu aprendi, lá no início, com a professorinha que dois menos três não dá. E ficou na mente deles isso até hoje, até você tirar, bloquear isso deles que de dois dá pra tirar três, é complicado para caramba. Ele está falando da dificuldade do aluno (referindo-se a outro professor que falou do tempo curto), eles têm dificuldade, eles ficaram muito tempo sem estudar, a maior parte dos alunos está há mais de trinta anos sem estudar, e eles vêm com essa mentalidade de que não dá para fazer isso. Você passar para eles que dá e começar a explicar para eles, demora um tempo, e quando esse tempo demora, você já tem que entrar em outro assunto, quando eles estão começando a entender, tem que mudar. Por causa do tempo".

Esse é um ponto frequentemente levantado pelos docentes de maneira geral, especialmente, pelos que atuam em turmas de educação de jovens e adultos. Recentemente, em reunião com professores da NEJA, o aspecto "tempo" foi levantado como um limitador. O ponto levantado pelo educador em tela, que se refere especificamente às dificuldades operacionais (e, implicitamente, conceituais com números inteiros) é um ponto particularmente sério, por gerar

\footnotetext{
${ }^{8}$ São aqueles que recorrentemente apresentam dificuldades de aprendizado pelos alunos ou que os professores possuem dificuldades em inovar no seu ensino, por exemplo, multiplicação de dois números negativos, operações com frações ou decimais, fatoração de expressões algébricas etc.
} 
entraves em todo o andamento do trabalho em aula, que tem influência, segundo esses professores, pelas dificuldades que os alunos apresentam em conceitos matemáticos básicos não aprendidos. A concordância dos outros docentes foi notória: não houve professor presente na sala que não manifestasse gestualmente ou em expressões que compactuavam com a fala do educador em tela.

No bloco seguinte ilustramos sugestões que emergiram ao longo das reflexões dos docentes de dois polos ${ }^{9}$ (Itaperuna e Nova Friburgo) para práticas formativas para EJA em Educação Matemática.

\section{Sobre o bloco temático Sugestões}

Professora de blusa branca (PBB): "De organizar umas aulas presenciais, como a gente já passa a manhã toda aqui, de trabalhar com a gente o GeoGebra, para a gente trabalhar com nosso aluno. Porque facilita muito nossa vida, entendeu".

A professora valoriza a utilização do software GeoGebra, pois destaca ser um grande recurso, que facilita e possibilita a exploração e manipulação do conhecimento. Destaca que seria muito interessante se fosse ofertada uma oficina para a manipulação do GeoGebra. Sugere o aproveitamento de que em algum horário, no encontro presencial, seja oferecida essa "capacitação". Embora muitos professores apresentem entusiasmo frente às novas tecnologias e softwares, muitos desconhecem como utilizá-los. Consequentemente, não sabem utilizar seus recursos de forma a potencializar sua utilização em sala. Logo, uma oficina que vise ao conhecimento funcional de algum recurso é uma ótima oportunidade de oferecer não só ao professor a ampliação de sua exploração em sala, mas também de proporcionar ao aluno uma outra maneira de visualizar e manipular o conhecimento.

\section{Resultados em reflexões finais}

Os resultados de nosso estudo enriquecem os de Silva e colaboradores (2013), particularmente, por oportunizarmos aos docentes reflexões in loco sobre seus modos de conceber, vivenciar e socializar práticas, ao mesmo tempo que lhes permite aprofundar aspectos de conteúdos concretos (CONTRERAS, 2002) de sua profissionalidade. A partir da realização de grupos focais videogravados, na análise realizada, vimos que o programa NEJA, ao colocar o aprendizado profissional docente como meta principal, tem se mostrado eficiente por promover uma formação em serviço que articule três âmbitos importantes no desenvolvimento profissional dos educadores: (1) suas concepções sobre a especificidade e relevância da EJA nos dias atuais, (2) a oportunidade de conhecer e vivenciar experiências variadas em sua própria prática com o material didático

\footnotetext{
${ }^{9}$ Em São João de Meriti não houve tempo para que os docentes fizessem sugestões devido ao tempo que os mesmos se dedicaram nos outros temas.
} 
produzido e (3) a possibilidade de participar de uma dinâmica de formação que propicie reflexões presenciais (nos encontros mensais) e compartilhamentos online constantes (nos fóruns de discussão).

Figura 1 - Âmbitos a serem potencializados na formação continuada em EJA.

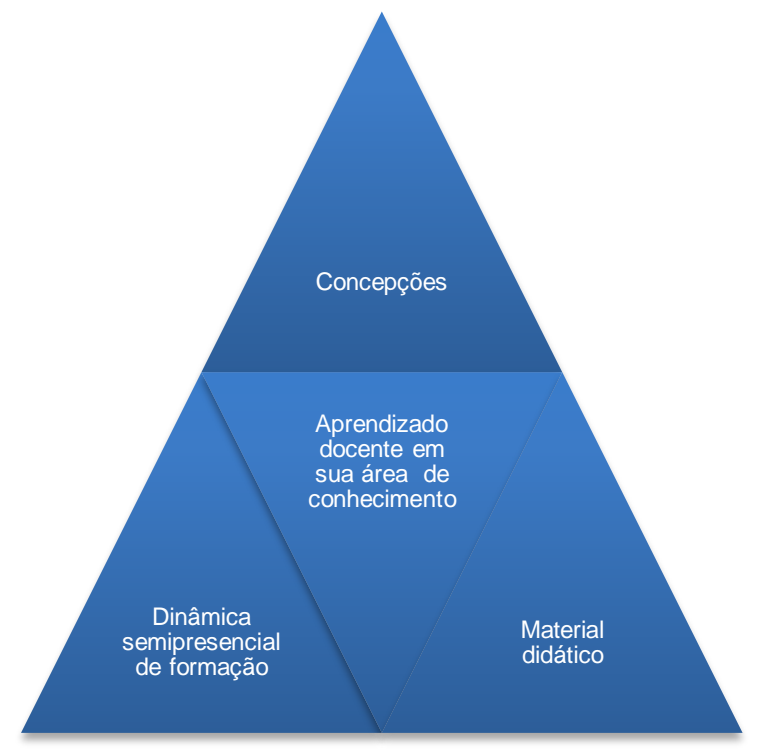

Fonte: Elaborado pelos autores.

Observamos que os professores valorizaram a formação recebida e perceberam a necessidade de uma formação específica para a EJA. Suas concepções revelaram uma aparente clareza sobre o propósito e a especificidade da NEJA, inclusive, como uma política pública. Suas reflexões também revelaram a atenção para a avaliação do aprendizado na EJA e para a importância de valorizar o conhecimento prévio dos estudantes.

Embora o tempo seja sempre um limitador para a implementação de práticas inovadoras para os docentes, eles reconheceram que o material didático propiciou-lhes aprender e a usar atividades e recursos presentes no material. Os educadores, inclusive, ressaltaram que o material foi inspirador para o ensino regular e mostraram interesse em conhecer mais sobre o trabalho - de forma presencial - com o software GeoGebra. Como uma política pública em fase de consolidação, pensamos ser importante ter um espaço para que os profissionais possam ser ouvidos e de modo que as demandas possam ser contempladas em novas edições do Programa.

A possibilidade de compartilhar e refletir coletivamente experiências com colegas de diferentes regiões do estado também favorece aos profissionais maior envolvimento e sugestões para novas edições do Programa. Esse posicionamento é muito pertinente em uma política pública que se reformula continuamente ouvindo os pares (equipe e cursistas), como foi o caso desta política, em particular. 


\section{Referências}

BERG, B. L. Qualitative research methods for the social sciences. Boston: Pearson: Allyn and Bacon, 2006.

CONTRERAS, J. A autonomia de professores. São Paulo: Cortez, 2002.

ESQUINCALHA. A. C.; PINTO, G. M. F.; BAIRRAL, M. A.; XAVIER, G. P. O.

Desenvolvimento e avaliação de material didático de Matemática: uma análise focada na reflexão dos professores. Revista de Educação, Ciências e Matemática, 5(2), p. 125-136, 2015.

ESQUINCALHA. A. C.; PINTO, G. M. F.; XAVIER, G. P. O.; BAIRRAL M. A. O

desenvolvimento profissional no Projeto Nova EJA da SEEDUC-/RJ: um olhar na formação continuada de professores que ensinam Matemática. Rio de Janeiro: CECIERJ, 2014.

FREITAS, M. L. Q.; RIBEIRO, N. N. A. Pesquisa Colaborativa: a (per) feição de uma nova pesquisa na Educação de Jovens e Adultos e a implicação dos sujeitos. Arquivos Analíticos de Políticas Educativas, 22(64), p. 1-15, 2014.

MINAYO, M. C. de S. O desafio do conhecimento: pesquisa qualitativa em saúde (4a . ed.). São Paulo-Rio de Janeiro: Hucitec-Abrasco, 1996.

PAIVA, J.; SALES, S. R. Contextos, perguntas, respostas: o que há de novo na educação de jovens e adultos? Arquivos Analíticos de Políticas Educativas, 21(69), p. 1-14, 2013.

RIO DE JANEIRO. Manual de Orientações Nova EJA. Disponível em http://projetoseeduc.cecierj.edu.br/eja/manual-eja.pdf. Acesso em 30 nov 2015.

SILVA, A. C. da; BASTOS, E. R. S.; RODRIGUES, C. G. da S.; SILVA, R. C. da; BRITO, A. M. F. Avaliação do Grau de Satisfação dos Professores de Matemática do Estado do Rio de Janeiro com o Curso de Formação Continuada Oferecido Pela Fundação CECIERJ: um estudo piloto.

Meta: Avaliação, 5(13), p. 126-157, 2013.

TASCA, J. E.; ENSSLIN, L.; ENSSLIN, S. R. A construção de um referencial teórico sobre a avaliação de desempenho de programas de capacitação. Ensaio: aval. pol. públ. Educ. [on-line], 21(79), p. 203-238, 2013. 